\title{
Genetic polymorphism of drug metabolizing enzymes (GSTM1 and CYP1A1) as risk factors for oral premalignant lesions and oral cancer
}

\author{
Deepika Shukla ${ }^{a}$, Alka Dinesh Kale ${ }^{b}$, Seema Hallikerimath ${ }^{b}$, Subbiah Vivekanandhanc, Yerrmalla Venkatakanthaiah`
}

\begin{abstract}
Aims. Polymorphisms in the genes that code for metabolic enzymes involved in either the activation (Phase I) or detoxication (Phase II) of chemical carcinogens in tobacco, may alter expression or function of carcinogenic compounds and hence alter risk of oral cancer. The present study investigates whether polymorphisms at CYP1A1 and GSTM1 gene loci act as risk factors for oral precancerous lesions and cancer.

Methods. For the present study, histopathologically confirmed cases of 90 oral precancerous lesions, 150 oral squamous cell carcinoma (SCC) and 150 control subjects were selected. Polymerase chain reaction and restriction fragment length polymorphism were performed using DNA from blood samples to determine the polymorphic genotypes at CYP1A1 and GSTM1 loci.

Results. CYP1A1 C (m2/m2) genotype conferred a 12.0 fold-increased risk (OR=12.0; 95\% Cl, 2.40-60.05) to oral SCC. GSTM1 null showed no significant association but the frequency was higher in oral SCC cases. Patients with genotype $C$ and/or GSTM1 deficiency developed carcinoma after less tobacco consumption than those of other genotypes though the difference was not statistically significant. The frequency of the combined genotypes C and GSTM1 null was found to be $14 \%$ among oral SCC patients. On comparing the susceptibility of intraoral sites it was found that in the majority of cases $(64 \%)$ in the study groups they were the buccal mucosa.

Conclusion. Hence it was concluded that metabolic enzymes reported in the present study: CYP1A1 significantly alter oral cancer risk. GSTM1 null and CYP1A1 C $(\mathrm{m} 2 \mathrm{~m} 2)$ show a predisposition to premalignant lesions and cancer of the buccal mucosa than other sites.
\end{abstract}

Key words: oral cancer, carcinogens, polymorphism, metabolic enzymes, CYP1A1, GSTM1

Received: July 20, 2011; Accepted with revision: January 12, 2012; Available online: January 30, 2012 http://dx.doi.org/10.5507/bp.2012.013

${ }^{a}$ Department of Oral Pathology and Microbiology, Faculty of Dentistry, Jamia Millia Islamia, Delhi, India ${ }^{b}$ Department of Oral Pathology and Microbiology, KLE VK Institute of Dental Sciences and Hospital, Belgaum, Karnataka, India 'Neurobiochemistry, Neurosciences Centre, All India Institute of Medical Sciences, New Delhi, India

Corresponding author:Deepika Shukla, e-mail:deepika_shukla06@yahoo.com

\section{INTRODUCTION}

Oral cancer is the most common cancer in males in India and is the third most common cancer in Indian females ${ }^{1}$. Among the more critical problems in clinical management are the lack of early detection and the increased frequency of local regional recurrence even with hard line surgical therapy. Thus it becomes essential to develop new molecular targets to be used as diagnostic and prognostic indicators.

Oral premalignant lesions such as leukoplakia and oral submucous fibrosis are early indicators of damage to the oral mucosa with a malignant transformation rate of $2-12 \%\left(\mathrm{ref}^{2}\right)$. Tobacco is an established etiological factor in the development of oral cancer. Most of these carcinogenic moieties are metabolically processed by xenobiotic metabolizing enzymes (XMEs) in two broad steps: phase I mediated by cytochrome p450s (CYPs) and phase II catalyzed by glutathione S-transferases (GSTs), $\mathrm{N}$-acetyltransferases, etc. Phase I reactions expose functional groups of the substrates and therefore yield highly reactive intermediates. These intermediates form the substrates for phase II reactions that involve their conjugation with endogenous molecules such as glutathione thus facilitate their elimination. Hence, the coordinated expression and regulation of phase I and II enzymes determines the outcome of carcinogen exposure ${ }^{3}$. Expression and function of these metabolizing enzymes may become altered by polymorphisms in the genes that code for them, thus increasing or decreasing the activation or detoxication of carcinogenic compounds ${ }^{4}$. An individual's exposure to tobacco carcinogens may therefore be altered by sequence variation in genes coding for these enzymes. These XMEs have received a great deal of attention recently as possible genetic susceptibility factors for various cancers.

The CYP1A1 gene codes for a phase I enzyme (aryl hydrocarbon hydroxylase) that activates tobacco procarcinogens like polyaromatic hydrocarbons and aromatic amines into their carcinogenic forms. Certain variant genotypes of the CYP1A1 gene which cause enhanced enzymatic activity appear to play a role in susceptibility to adduct formation and presumably cancer risk ${ }^{5}$. The CYP1A1 MspI polymorphism which results from a single base pair change at nucleotide position 264 from the poly (A) signal in the 3' untranslated region of the CYP1A1 gene, is found in $5-30 \%$ of the population $\left(\right.$ ref. $\left.^{6-8}\right)$. It has 


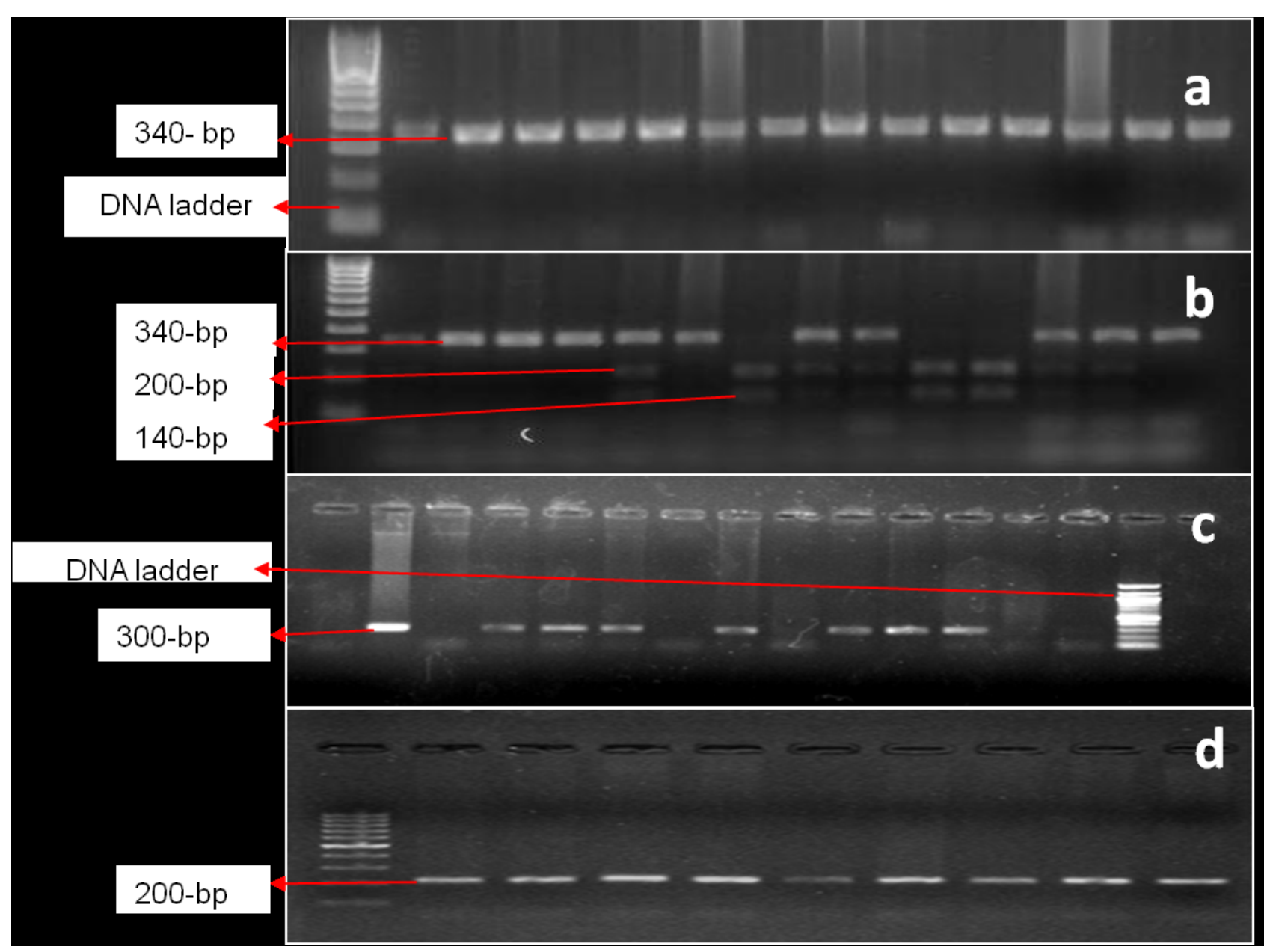

Fig. 1. Photograph showing gel electrophoresis results of PCR amplified products for study group a) Gel picture showing CYP1A1 genotype (CYP1A1 PCR prduct size is $340 \mathrm{bp}$ ). b) Gel picture showing polymorphism of CYP1A1 genotype after restriction digestion with MSP I enzyme. Wild type produced 340-bp band, whereas the variant produced bands at 200 and 140-bp. Homozygous CYP1A1 A [m1/m1]: produced bands at 340-bp. Heterozygous CYP1A1 B[m1/m2]: produced bands at 340, 200 and 140-bp. Homozygous CYP1A1 C[m2/m2]: produced bands at 200 and 140-bp. c) Gel picture showing polymorphism of GSTM1 genotype (GSTM1 PCR product size 300bp). d) Gel picture showing presence of globin gene (Globin PCR product size $200 \mathrm{bp}$ ).

been associated with higher risk of tobacco-related cancers, such as oral and lung cancers ${ }^{9}$. The glutathione $\mathrm{S}$ transferase (GST) family includes phase II enzymes that detoxify carcinogens, reactive oxygen species and lipid peroxidation products, yielding excretable hydrophilic metabolites ${ }^{10}$. Individuals who have homozygous deletions for the GSTM1 gene have no GSTM1 enzyme activity. Lack of these enzymes may potentially increase susceptibility to various cancers because of a decreased ability to detoxify carcinogens such as benzo[a]pyrene-7, 8-diol epoxide, the activated form of benzo[a]pyrene $e^{9,11}$.

Oral precancerous lesions and oral squamous cell carcinoma (SCC) constitute a significant public health burden, particularly in India. However there have been a relatively small number of epidemiological studies that have examined the impact of genetic determinants on host susceptibility to this oral disease in Indian populations. Thus the present study investigates the role of polymorphisms at CYP1A1 and GSTM1 gene loci and susceptibility to oral precancerous lesions and cancer. The possibility of altered susceptibility among different intra- oral sites and association between metabolizing enzymes genotype prevalence and exposure to risk factors in oral cancer induction is also explored.

\section{MATERIALS AND METHODS}

\section{Study subjects}

For the present study, histopathologically confirmed cases of 90 oral precancerous lesions, 150 oral SCC, and 150 control subjects were selected. These patients reported to Institute of Dental Sciences KLE University, KLE's Prabhakar Kore Hospital \& Medical Research Centre, Belgaum Cancer Hospital and Padmashree Dr. R.B. Patil Cancer Hospital Hubli for Oral precancerous lesions and Oral SCC. Ethical Committee approval was obtained prior to the start of the study. Informed consent was taken from all participants. Information regarding age, gender, occupation and details about duration, frequency, nature of tobacco habit (smoking or nonsmoking), alcohol consumption, medical history and family history of cancer 
were recorded. Patients with known systemic disease and/ or patients with metastasis from primary Oral SCC to other regions of the body were excluded. Controls enrolled in this study were matched for age, gender and tobacco habits. Control subjects included patients seen in the same hospital with conditions requiring dental treatment.

The incisional biopsy was performed under local anesthesia on the suspected lesion. The biopsy specimens were fixed in neutral buffer formalin. Routine processing, sectioning and staining with haematoxylin and eosin was done for histological confirmation. Patients with precancerous lesions had leukoplakia and submucous fibrosis that was histopathologically confirmed. Cancer cases were patients with cancers of the oral cavity, i.e., buccal mucosa, alveolus, lip, palate, floor of the mouth and tongue. All cancers were confirmed histopathologicaly to be SCC.

\section{Genotyping}

Five milliliters of venous blood was collected from all study subjects in vacutainer tubes containing EDTA using aseptic measures. The blood was stored at $-20{ }^{\circ} \mathrm{C}$ and transported in ice to the laboratory. DNA was extracted from peripheral blood lymphocytes by standard RNase and proteinase $\mathrm{K}$ treatment and phenol-chloroform extraction. DNA samples are stored at $-200{ }^{\circ} \mathrm{C}$ until further reactions. DNA samples were evaluated for quantity by spectrophotometry (by NanoDrop ND-1000 spectrophotometer) and quality by a $1 \%$ agarose gel run. Polymerase chain reaction (PCR) and restriction fragment length polymorphism (RFLP) was performed using DNA samples to determine the polymorphic genotypes at CYP1A1 and GSTM1 loci. The reaction mixtures underwent the following incubations in Applied Biosystems 2720 thermal cycler: 1 cycle of $96{ }^{\circ} \mathrm{C}$ for $30 \mathrm{~s}, 30$ cycles of $94{ }^{\circ} \mathrm{C}$ for $30 \mathrm{~s}, 56{ }^{\circ} \mathrm{C}$ for $40 \mathrm{~s}$, and $72{ }^{\circ} \mathrm{C}$ for $30 \mathrm{~s}$, followed by a final cycle of $7 \mathrm{~min}$ at $72^{\circ} \mathrm{C}$. Samples were electrophoresed on $2 \%$ native polyacrylamide gels, stained with ethidium bromide and examined over UV light (UV Transilluminator).

Genotypes were analyzed using PCR-based methods as described below.

\section{CYP1A1}

The CYP1A1 mutation found in the 3-flanking region was detected by PCR (Fig. 1) and RFLP analysis using the MspI restriction enzyme ${ }^{12}$. The DNA fragment was amplified using the following primers: 5'-CAG-TGAAGAGGT-GTA-GCC-GCT-3' and 5'-TAG-GAG-TCTTGTCTC-ATG-CCT-3'. After amplification, the PCR product was subjected to restriction digestion using MspI. The products were then separated by agarose gel ( $2 \%$ gel) electrophoresis. The CYP1A1 polymorphisms were classified as homozygous for $\mathrm{m} 1 / \mathrm{m} 1$ (CYP1A1 A genotype which produced a 340-bp band), heterozygous for $\mathrm{m} 1 /$ m2 (CYP1A1 B genotype which produced 340, 200 and 140-bp bands), or homozygous for m2/m2 (CYP1A1 C genotype which produced 200 and 140-bp bands) alleles (Fig. 1).

\section{GSTM1}

The GSTM1 genotype was detected after PCR amplification using primers for the GSTM1 gene ${ }^{13}$ and the globin gene. The GSTM1 primers were 5'-CTG-CCCTAC-TTGATT-GAT-GGG-3' and 5'-CTG-GAT-TGTAGC-AGA-TCATGC-3'. The wild-type samples produced a band at $300 \mathrm{bp}$. In the variant samples, the GSTM1 gene was absent (GSTM1 null), and no band was observed (Fig. 1).

\section{Globin gene}

A portion of the globin gene was amplified as a positive control, producing a 200-bp fragment (Fig. 1). The following primers were used: 5'-GAA-GAG-CCA-AGGACA-GGTAC- 3' and 5'-GGT-GTC-TGT-TTG-AGG-TTGCT-3'.

\section{Statistical analysis}

Statistical analysis was performed using the SPSS software (version 11.5). Frequency distributions of the various genotypes were examined among cases and controls and also among different habit groups. The Chi-square test was used for comparison of proportions. Risks were estimated using conditional logistic regression to calculate the odds ratios (OR) and 95\% confidence intervals (CI) among cases and controls after age adjustment.

\section{RESULTS}

\section{Cohort Characterstics}

A total of 240 cases ( 90 premalignant, 150 oral SCC) and 150 controls were entered into the study. The age group of premalignant lesions showed significant difference $(P<0.05$; Table 1$)$ with other groups indicating that these lesions were more common among the younger age group in contrast to oral SCC cases which were common in the older age group. There was no significant difference between groups with respect to gender $(P<0.05)$. In all groups the majority were males (78\%, Table 1$)$.

The majority $(77 \%)$ in the study groups were chewers (Fig. 2). To evaluate gene-tobacco interactions, the prevalence of CYP1A1 and GSTM1 were stratified by tobacco history. As expected, oral SCC cases had a significantly higher level of overall tobacco consumption (including betel quid (BQ), bidi smoking; $P<0.05$; Table 1). Similarly oral cancer patients had significantly higher frequency and duration of tobacco consumption than controls $(P<0.05)$. Lifetime exposure was calculated among all tobacco users for both cases and controls. (Lifetime exposure $=$ Frequency of chewing events per day X Duration in years X 365 ). Lifetime exposure for tobacco consumption revealed that oral cancer patients were maximally exposed as compared to controls.

\section{Gene interactions within various exposure groups}

For the premalignant and oral SCC group, genotype was compared with nature and lifetime exposure of to- 


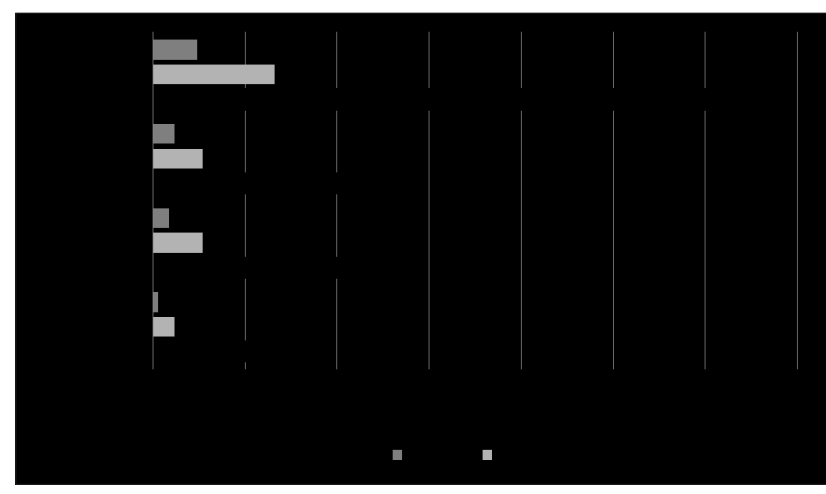

Fig. 2. Types of habits in the study group. Maximum cases $(77 \%)$ in study groups were chewers.

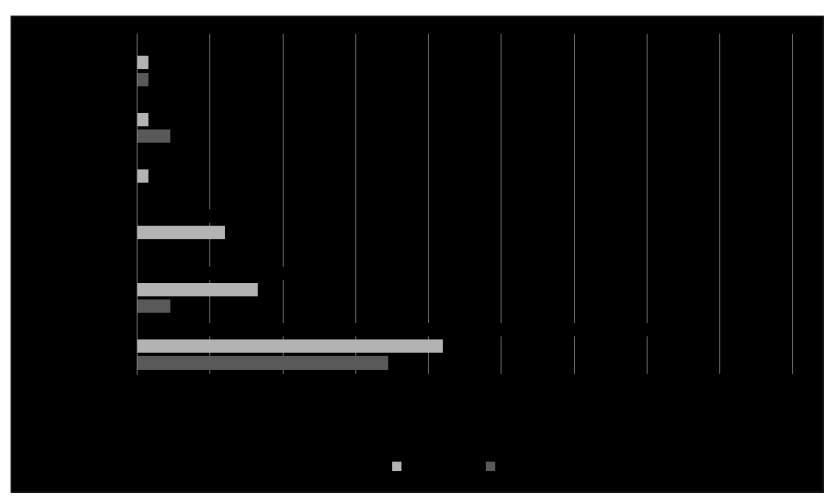

Fig. 3. Analysis with respect to intraoral site of lesion in the study groups. The majority of cases [64\%] in the study groups were from buccal mucosa.

Table 1. Characteristics of patients with MspI genotypes of CYP1A1 and GSTM1 genotypes.

\begin{tabular}{|c|c|c|c|c|c|c|c|c|}
\hline Group & Genotype & $\begin{array}{c}\text { No. of } \\
\text { patients, } \\
\text { n[\%] }\end{array}$ & Male & Female & $\begin{array}{c}\text { Age } \\
{[\text { mean } \pm S D]}\end{array}$ & $\begin{array}{l}\text { Tobacco } \\
\text { mean dura- } \\
\text { tion }\end{array}$ & $\begin{array}{c}\text { Mean } \\
\text { Frequency }\end{array}$ & $\begin{array}{c}\text { Lifetime } \\
\text { exposure } \\
{\left[\mathrm{X} 10^{4}\right]}\end{array}$ \\
\hline \multirow{4}{*}{$\begin{array}{l}\text { Premalignant } \\
\text { lesions }\end{array}$} & $\begin{array}{l}\text { CYP1A1 } \\
\text { A[m1m1] }\end{array}$ & $57[63.3]$ & 48 & 9 & $44.1 \pm 16.24$ & $8.84 \pm 5.45$ & $6.68 \pm 2.00$ & 2.25 \\
\hline & $\mathrm{B}[\mathrm{m} 1 \mathrm{~m} 2]$ & $21[23.3]$ & 15 & 6 & $30.86 \pm 9.58$ & $12.5 \pm 6.20$ & $7.5 \pm 2.44$ & 2.63 \\
\hline & $\mathrm{C}[\mathrm{m} 2 \mathrm{~m} 2]$ & $12[13.3]$ & 9 & 3 & $25.5 \pm 3.70$ & $8.00 \pm 4.08$ & $7.80 \pm 3.19$ & 4.91 \\
\hline & $\begin{array}{l}\text { GSTM1 } \\
\text { Present }\end{array}$ & $60[69]$ & 54 & 6 & $41.35 \pm 17.62$ & $8.75 \pm 4.74$ & $7.2 \pm 3.49$ & 2.33 \\
\hline Total & GSTM1null & $\begin{array}{c}27[31] \\
90\end{array}$ & $\begin{array}{c}15 \\
72[80]\end{array}$ & $\begin{array}{c}12 \\
18[20]\end{array}$ & $\begin{array}{l}32.33 \pm 8.33 \\
32.33 \pm 8.76\end{array}$ & $\begin{array}{c}9.22 \pm 6.91 \\
8.8 \pm 5.31\end{array}$ & $\begin{array}{l}9.56 \pm 4.56 \\
7.87 \pm 3.88\end{array}$ & $\begin{array}{l}3.66 \\
2.79\end{array}$ \\
\hline \multirow{5}{*}{ Oral SCC } & $\begin{array}{l}\text { CYP1A1 } \\
\text { A[m1m1] }\end{array}$ & $45[30]$ & 36 & 9 & $54.67 \pm 9.54$ & 63 & .86 & 7.21 \\
\hline & $\mathrm{B}[\mathrm{m} 1 \mathrm{~m} 2]$ & $60[40]$ & 51 & 9 & $54.35 \pm 10.34$ & $17.75 \pm 7.57$ & $8.95 \pm 3.89$ & 5.84 \\
\hline & $\mathrm{C}[\mathrm{m} 2 \mathrm{~m} 2]$ & $45[3$ & 30 & 15 & $50.07 \pm 10.45$ & 85 & $8.6^{\circ}$ & $\begin{array}{c}4.44 \\
{[P=0.72]}\end{array}$ \\
\hline & GSTM1p & $99[66]$ & 81 & 18 & $50.09 \pm 10.28$ & $15.55 \pm 7.40$ & $9.91 \pm 5.31$ & 6.03 \\
\hline & GSTM1null & $51[34]$ & 36 & 15 & $59.12 \pm 6.83$ & $18.00 \pm 7.66$ & $8.29 \pm 3.50$ & 5.45 \\
\hline Total & & 150 & $117[78]$ & $33[22]$ & $53.16 \pm 10.14$ & $16.38 \pm 7.50$ & $9.36=$ & 5.83 \\
\hline \multirow{5}{*}{$\begin{array}{l}\text { Healthy } \\
\text { control }\end{array}$} & $\begin{array}{l}\text { CYP1A1 } \\
\text { A[m1m1] }\end{array}$ & $72[42]$ & 57 & 15 & $50.38 \pm 16.26$ & $5.5 \pm 2.77$ & $6.25 \pm 2.38$ & 1.21 \\
\hline & $\mathrm{B}[\mathrm{m} 1 \mathrm{~m} 2]$ & $72[42]$ & 54 & 18 & $48.96 \pm 14.97$ & $6.29 \pm 5.75$ & $5.04 \pm 2.49$ & 1.02 \\
\hline & $\mathrm{C}[\mathrm{m} 2 \mathrm{~m} 2]$ & $6[4]$ & 3 & 3 & $54.5 \pm 12.02$ & $5.50 \pm 0.71$ & $6.00 \pm 6.00$ & 1.21 \\
\hline & GSTM1present & $114[80.9]$ & 93 & 21 & $51.58 \pm 13.53$ & $5.90 \pm 4.83$ & $5.42 \pm 2.41$ & 1.06 \\
\hline & GSTM1null & $27[19.1]$ & 12 & 15 & $46.59 \pm 17.82$ & $6.56 \pm 2.65$ & $6.33 \pm 2.18$ & 1.48 \\
\hline Total & & 150 & $114[76]$ & $36[24]$ & $49.86 \pm 15.29$ & $5.88 \pm 4.39$ & $5.66 \pm 2.44$ & 1.12 \\
\hline
\end{tabular}

- NR-no representation of variant genotype [globin gene absent].

- $3 \mathrm{NR}$ in premalignant group and $9 \mathrm{NR}$ in controls.

bacco consumption. The odds ratio was not found to be significant.

\section{Differential susceptibility among intra-oral sites}

When differentiating by major tumor sites, there appeared to be an increased prevalence of the GSTM1 null genotype in patients with oral cancer of the buccal mucosa, but this was not statistically significant given the low number of recruited cases with this disease. GSTM1 and CYP1A1 C (m2m2) shows predisposition to premalignant lesions and cancer of buccal mucosa than of other sites [data not shown].

Distribution of MspI genotypes of CYPIAI and GSTMI genotypes among Cases and Healthy controls

CYP1A1 genotypes A $(\mathrm{m} 1 / \mathrm{m} 1), B(\mathrm{~m} 1 / \mathrm{m} 2)$ and C $(\mathrm{m} 2 / \mathrm{m} 2)$ were found in $72(42 \%), 72(42 \%)$ and $6(4 \%)$ individuals, respectively, among the healthy controls. 
Table 2. Distribution of MspI genotypes of CYP1A1 and GSTM1 genotypes among premalignant lesions, Oral SCC cases and healthy controls.

\begin{tabular}{|c|c|c|c|c|c|}
\hline & $\begin{array}{c}\text { Healthy } \\
\text { Controls, } \mathrm{n}[\%]\end{array}$ & $\begin{array}{l}\text { Premalignant } \\
\text { lesions, } n[\%]\end{array}$ & $\begin{array}{l}\text { Odds Ratio } \\
(95 \% \text { CI })\end{array}$ & $\begin{array}{c}\text { Oral SCC, } \\
\mathrm{n}[\%]\end{array}$ & $\begin{array}{l}\text { Odds Ratio } \\
(95 \% \text { CI })\end{array}$ \\
\hline \multicolumn{6}{|l|}{ CYP1A1 } \\
\hline $\mathrm{A}[\mathrm{m} 1 \mathrm{~m} 1]$ & $72[42]$ & $57[63.3]$ & 1 & $45[30]$ & 1 \\
\hline $\mathrm{B}[\mathrm{m} 1 \mathrm{~m} 2]$ & $72[42]$ & $21[23.3]$ & $0.37[0.13-1.04]$ & $60[40]$ & $1.33[0.56-3.20]$ \\
\hline $\mathrm{C}[\mathrm{m} 2 \mathrm{~m} 2]$ & $6[4]$ & $12[13.3]$ & $2.53[0.4-15.30]$ & $45[30]$ & $12.00[2.40-60.05]^{*}$ \\
\hline \multicolumn{6}{|l|}{ GSTM1 } \\
\hline GSTM1present & $114[80.9]$ & $60[69]$ & 1 & $99[66]$ & 1 \\
\hline GSTM1null & $27[19.1]$ & $27[31]$ & $1.90[0.65-5.52]$ & $51[34]$ & $2.18[0.86-5.53]$ \\
\hline $\begin{array}{l}\text { A[m1m1] } \\
\text { GSTM1present }\end{array}$ & $57[40.4]$ & $42[48.3]$ & 1 & $27[18]$ & 1 \\
\hline $\begin{array}{l}\text { A[m1m1] } \\
\text { GSTM1null }\end{array}$ & $15[10.6]$ & $12[13.8]$ & $1.09[0.25-4.79]$ & $18[12]$ & $2.53[0.61-10.56]$ \\
\hline $\begin{array}{l}\text { B[m1m2] } \\
\text { GSTM1present }\end{array}$ & $51[36.2]$ & $12[13.8]$ & 1 & $48[32]$ & 1 \\
\hline $\begin{array}{l}\text { B[m1m2] } \\
\text { GSTM1null }\end{array}$ & $12[8.5]$ & $9[10.3]$ & $3.19[0.50-20.30]$ & $12[8]$ & $1.06[0.23-4.98]$ \\
\hline $\begin{array}{l}\mathrm{C}[\mathrm{m} 2 \mathrm{~m} 2] \\
\text { GSTM1present }\end{array}$ & $6[4]$ & $6[6.9]$ & - & $24[16]$ & $4.25[0.78-23.11]$ \\
\hline $\begin{array}{l}\text { C[m2m2] } \\
\text { GSTM1null }\end{array}$ & $0[0]$ & $6[6.9]$ & - & $21[14]$ & - \\
\hline
\end{tabular}

On the other hand, types $\mathrm{A}(\mathrm{m} 1 / \mathrm{m} 1), \mathrm{B}(\mathrm{m} 1 / \mathrm{m} 2)$ and $\mathrm{C}(\mathrm{m} 2 / \mathrm{m} 2)$ were found in $57(63 \%), 21(23 \%)$ and 12 (13\%) oral precancerous patients and 45 (30\%), 60 (40\%) and $45(30 \%)$ oral SCC patients. Patients with oral SCC were more likely to have homozygous CYP1A1 C (m2/ $\mathrm{m} 2$ ) genotypes when compared to controls $(\mathrm{OR}=12.00$, 95\% CI=2.40-60.05: Table 2).

For matched cases and controls, the homozygous GSTM1null genotype, as evidenced by the sole presence of a 300-bp fragment corresponding to globin gene was observed in $19 \%$ of subjects in controls, $31 \%$ in premalignant group and $34 \%$ in oral SCC group.

Combined genotyping of the CYP1A1 and GSTM1 genes and oral SCC incidence

The frequency of the combined genotypes $\mathrm{C}$ and GSTM1 null was $14 \%$ in oral SCC cases as compared to $0 \%$ in healthy controls. In premalignant group, frequency of CYP1A1 C and GSTM1 null genotypes was more than the control group but no significant association was found.

\section{DISCUSSION}

A total of 240 cases (90 premalignant, 150 oral SCC) and 150 controls were subjected for genotype analysis in the present study. The majority of patients with oral precancerous and cancerous lesions were males (74\%) which is in concurrence with the literature. With respect to age, premalignant lesions were significantly more common in the younger age group (Mean age 32.33 \pm 8.76 ) as compared to oral SCC which was more prevalent in the older age group $(53.16 \pm 10.14 ; P<0.05$; Table 1$)$. The reason for premalignant lesions being more common in the second and third decades of life may be a function of personal factors, coupled with a weak family structure or support, adult role modeling, peer influences and sports team membership ${ }^{14}$. This was consistent with a study by Hashibe et al. ${ }^{15}$ who reported increased risk of premalignant lesions in a young population in the United States exposed to the similar tobacco products. Recently studies have shown that in tobacco smokers, a young age was associated with higher levels of DNA adducts and altered oral mucosal cell proliferation rates ${ }^{16,17}$. All of these can potentially contribute to altered sensitivity to carcinogens.

In the present study, the frequency and duration of tobacco consumption was significantly higher in the oral cancer group than controls $(P<0.05$; Table 1$) .62 \%$ of oral carcinoma cases and $20 \%$ of precancerous lesions consumed tobacco for $>/=15$ years whereas only $4 \%$ of the controls fell into this group. The figure clearly indicates that oral cancer patients were maximally exposed 
(lifetime exposure for tobacco consumption: $5.83-8.31$ $\left.\mathrm{X} 10^{4}\right)$. Further the majority of cases $(77 \%)$ were chewers (Fig. 2) suggesting that the tobacco chewing habit with or without the BQ, prevalent in India also contributes to increased risk of oral cancer, due to additional exposure to alkaloids and polyphenols from the areca nut whereas in western countries, cigarette smoking and heavy alcohol consumption are the main risk factors ${ }^{18}$. Smokers constituted a low percentage of subjects, and therefore the risk due to smoking could not be seen.

Further, when the role of polymorphisms at the CYP1A1and GSTM1 gene loci and susceptibility to oral precancerous lesions and cancer was explored, CYP1A1 $\mathrm{C}(\mathrm{m} 2 / \mathrm{m} 2)$ genotype was found in $30 \%$ of oral SCC patients, a statistically significant incidence, about seven times higher than that of healthy controls (4\%). CYP1A1 $\mathrm{C}(\mathrm{m} 2 / \mathrm{m} 2)$ genotype conferred a 12.0 fold-increased risk (95\% CI, 2.40-60.05) to oral SCC. This observation is consistent with a report of SCC of lung ${ }^{19}$. The association between this polymorphism and oral cancer susceptibility observed in the present study is consistent with the high levels of CYP1A1 enzyme present in oral tissue ${ }^{20}$.

Subsequently, the incidence of the GSTM1 gene presence or its complete deletion (GSTM1 null) between patients and controls were compared. The frequency of the GSTM1 null genotype in controls was $19 \%$ and that in oral SCC patients was 34\%. Although GSTM1 null did not show a significant association the frequency was higher in oral SCC cases. The frequency of GSTM1 null genotypes among control subjects in this study population (19\%) lay within the range of $17-38 \%$ reported among the Indian population (ref. ${ }^{21,22}$ ). Studies have shown both positive and negative associations of GSTM1 null genotype with oral cancer risk in different worldwide populations. It is worth noting, however, that among the Japanese, the majority of oral cancer studies have observed positive association which can be explained by the high frequency $(>50 \%)$ of homozygous null genotype in this population (ref. ${ }^{19}$ ). In the present study conducted on a south Indian population, no significant association was observed between risk of Oral SCC and GSTM1 homozygous null genotype. The observed lack of a significant association between the GSTM1 null genotype and susceptibility to oral cancer in the present study is similar to that observed in previous studies ${ }^{23,24}$.

Vaury etal hypothesized that the CYP1A1 genoype and GSTM1 null interactions result in a greater-than-additive risk for DNA damage and cancer ${ }^{25}$. Moreover, Vaury also showed that in human cells, deletion of GSTM1 is associated with strong inducibility of CYP1A1 gene transcription by 2,4,7,8-tetrachlorodibenzo-para-dioxin, suggesting that this genotype combination predisposes to an increased risk for tobacco-associated DNA damage. In the present study, the frequency of the combined genotypes CYP1A1 C and GSTM1 null was significantly more in oral SCC patients (14\%) compared to healthy controls $(0 \%)$. However, it is not certain whether these two genes worked synergistically to enhance the risk of oral SCC because there were insufficient subjects for an adequate analysis on the basis of odds ratios.

Next, estimating the cumulative tobacco dose for patients exhibiting MspI genotypes of CYP1A1, it was found that SCC patients with genotype $\mathrm{C}$ had a relatively lower dose (lifetime exposure: $4.44 \times 10^{4}$ ) than patients with genotypes A (lifetime exposure: 7.81X10 ${ }^{4}$ ) and B (lifetime exposure: $5.24 \times 10^{4}$ ). Also, the estimated tobacco dose for patients with GSTM1 null (lifetime exposure: 5.45X104) was less than for GSTM1 present (lifetime exposure: $6.03 \times 10^{4}$ ) patients. It is suspected that the genotypes $\mathrm{C}$ and GSTM1 null play an important role in individual differences in susceptibility to oral SCC, especially to the lowest tobacco dose level. The results of this study revealed that genetically predisposed BQ/tobacco chewers are much more susceptible to environmental and life-style risk factors.

Another interesting finding was that thr majority of cases $(64 \%)$ in the study groups were from the buccal mucosa. The number itself indicates that GSTM1 and CYP1A1 C (m2m2) shows a predisposition to premalignant lesions and more cancer of the buccal mucosa than other sites (Fig. 3). Such differences in genetic susceptibility to cancers have been previously reported within sites of the oral cavity ${ }^{26,27}$. Tanimoto et al also reported that patients carrying the combination of homozygous CYP1A1 (m1/m1) and GSTM1 presented a significantly increased risk for oral squamous cell carcinoma, with the buccal mucosa and upper gingiva appearing to be the most susceptible tissues in patients carrying this "risk" genotype. The authors further reported that of the various subsites of oral cancer, except for the floor of the mouth, ORs ranged from 2.3 (tongue) to 46.5 (buccal mucosa) $\left(\right.$ ref. $\left.^{26}\right)$. It is known that differences exist in the incidence of cancers among various regions of the oral cavity and these are in part explained by differences in the biological function of these organs ${ }^{28}$.

\section{CONCLUSION}

Of metabolic enzymes reported in the present study: CYP1A1 significantly alters oral cancer risk. Knowledge of the prevalence and distribution of common genetic susceptibility factors and the ability to identify susceptible individuals or subgroups will have substantial preventive implications, in particular if more data are collected to show that people with certain "at risk" genotypes are more susceptible to low levels of exposure.

\section{ABBREVIATIONS}

Bp, Base pair; BQ, Betel quid; CYP, Cytochrome P450; CI, Confidence intervals; EDTA, Ethylenediaminetetraacetic acid; GST, Glutathione S transferase; OR, Odds ratios; PCR, Polymerase chain reaction; RFLP, Restriction fragment length polymorphism; SCC, Squamous cell carcinoma; SD, Standard deviation. 


\section{CONFLICT OF INTEREST STATEMENT}

Author's conflict of interest disclosure: The authors stated that there are no conflicts of interest regarding the publication of this article.

\section{REFERENCES}

1. Rai R, Kulkarni V, Saranath D. Genome wide instability scanning in chewing-tobacco associated oral cancer using inter simple sequence repeat PCR.Oral Oncol 2004;40:1033-9.

2. Sanchez-Cespedes M, Esteller M, Wu L, Nawroz-Danish H, Yoo GH, Koch WM, Jen J, Herman JG, Sidransky D. Gene promoter hypermethylation in tumors and serum of head and neck cancer patients. Cancer Res 2000;60:892-5.

3. Bartsch H, Nair U, Risch A, Rojas M, Wikman H, Alexandrov K. Genetic polymorphism of CYP genes, alone or in combination, as a risk modifier of tobacco-related cancers. Cancer Epidemiol Biomarkers Prev 2000;9:3-28.

4. Olshan AF, Weissler MC, Watson MA, Bell DA. GSTM1, GSTT1, GSTP1, CYP1A1, and NAT1 polymorphisms, tobacco use, and the risk of head and neck cancer. Cancer Epidemiol Biomarkers Prev 2000;9:185-91.

5. Rojas M, Cascorbi I, Alexandrov K, Kriek E, Auburtin G, Mayer L, KoppSchneider A, Roots I, Bartsch H. Modulation of benzo[a]pyrene diolepoxide-DNA adduct levels in human white blood cells by CYP1A1, GSTM1 and GSTT1 polymorphism. Carcinogenesis 2000;21:35-41.

6. Sugimura H, Suzuki I, Hamada GS, Iwase T, Takahashi T, Nagura K Iwata H, Watanabe S, Kino I, Tsugane S. Cytochrome P-450 IA1 genotype in lung cancer patients and controls in Rio de Janeiro, Brazil. Cancer Epidemiol Biomarkers Prev 1994;3:145-8.

7. Shields PG, Caporaso NE, Falk RT, Sugimura H, Trivers GE, Trump BF, Hoover RN, Weston A, Harris CC. Lung cancer, race, and a CYP1A1 genetic polymorphism. Cancer Epidemiol Biomarkers Prev 1993;2:4815.

8. Kawajiri K, Nakachi K, Imai K, Yoshii A, Shinoda N, Watanabe J. Identification of genetically high risk individuals to lung cancer by DNA polymorphisms of the cytochrome P450IA1 gene. FEBS Lett 1990;263:131-3.

9. Hashibe M, Brennan P, Strange RC, Bhisey R, Cascorbi I, Lazarus $P_{1}$ Oude Ophuis MB, Benhamou S, Foulkes WD, Katoh T, Coutelle C, Romkes M, Gaspari L, Taioli E, Boffetta P. Meta- and pooled analyses of GSTM1, GSTT1, GSTP1, and CYP1A1 genotypes and risk of head and neck cancer. Cancer Epidemiol Biomarkers Prev 2003;12:150917.

10. Jancova P, Anzenbacher P, Anzenbacherova E. Phase II drug metabolizing enzymes. Biomed Pap Med Fac Univ Palacky Olomouc Czech Repub;154:103-16.

11. Katoh T, Nagata N, Kuroda Y, Itoh H, Kawahara A, Kuroki N, Ookuma R, Bell DA. Glutathione S-transferase M1 (GSTM1) and T1 (GSTT1) genetic polymorphism and susceptibility to gastric and colorectal adenocarcinoma. Carcinogenesis 1996;17:1855-9.
12. Kawajiri K, Watanabe J, Hayashi S. Identification of allelic variants of the human CYP1A1 gene. Methods Enzymol 1996;272:226-32.

13. Comstock KE, Sanderson BJ, Claflin G, Henner WD. GST1 gene deletion determined by polymerase chain reaction. Nucleic Acids Res 1990;18:3670.

14. Tomar SL, Giovino GA. Incidence and predictors of smokeless tobacco use among US youth. Am J Public Health 1998;88:20-6.

15. Hashibe M, Mathew B, Kuruvilla B, Thomas G, Sankaranarayanan R, Parkin DM, Zhang ZF. Chewing tobacco, alcohol, and the risk of erythroplakia. Cancer Epidemiol Biomarkers Prev 2000;9:639-45.

16. Wiencke JK, Thurston SW, Kelsey KT, Varkonyi A, Wain JC, Mark EJ, Christiani DC. Early age at smoking initiation and tobacco carcinogen DNA damage in the lung. J Natl Cancer Inst 1999;91:614-9.

17. Trock B. Out of the mouths of babes: oral premalignant lesions and use of alternative tobacco products. Cancer Epidemiol Biomarkers Prev 2000;9:637-8.

18. La Vecchia C, Tavani A, Franceschi S, Levi F, Corrao G, Negri E. Epidemiology and prevention of oral cancer. Oral Oncol 1997;33:30212.

19. Sato M, Sato T, Izumo T, Amagasa T. Genetic polymorphism of drug-metabolizing enzymes and susceptibility to oral cancer. Carcinogenesis 1999;20:1927-31.

20. Setiawan VW, Zhang ZF, Yu GP, Li YL, Lu ML, Tsai CJ, Cordova D, Wang MR, Guo CH, Yu SZ, Kurtz RC. GSTT1 and GSTM1 null genotypes and the risk of gastric cancer: a case-control study in a Chinese population. Cancer Epidemiol Biomarkers Prev 2000;9:73-80.

21. Nair UJ, Nair J, Mathew B, Bartsch H. Glutathione S-transferase M1 and $\mathrm{T} 1$ null genotypes as risk factors for oral leukoplakia in ethnic Indian betel quid/tobacco chewers. Carcinogenesis 1999;20:743-8.

22. Buch SC, Notani PN, Bhisey RA. Polymorphism at GSTM1, GSTM3 and GSTT1 gene loci and susceptibility to oral cancer in an Indian population. Carcinogenesis 2002;23:803-7.

23. Park JY, Muscat JE, Ren Q, Schantz SP, Harwick RD, Stern JC, Pike V, Richie JP, Jr., Lazarus P. CYP1A1 and GSTM1 polymorphisms and oral cancer risk. Cancer Epidemiol Biomarkers Prev 1997;6:791-7.

24. Sreelekha TT, Ramadas K, Pandey M, Thomas G, Nalinakumari KR, Pillai MR. Genetic polymorphism of CYP1A1, GSTM1 and GSTT1 genes in Indian oral cancer. Oral Oncol 2001;37:593-8.

25. Vaury C, Laine R, Noguiez P, de Coppet P, Jaulin C, Praz F, Pompon D, Amor-Gueret M. Human glutathione S-transferase M1 null genotype is associated with a high inducibility of cytochrome P450 $1 \mathrm{~A} 1$ gene transcription. Cancer Res 1995;55:5520-3.

26. Tanimoto K, Hayashi S, Yoshiga K, Ichikawa T. Polymorphisms of the CYP1A1 and GSTM1 gene involved in oral squamous cell carcinoma in association with a cigarette dose. Oral Oncol 1999;35:191-6.

27. Anantharaman D, Chaubal PM, Kannan S, Bhisey RA, Mahimkar MB. Susceptibility to oral cancer by genetic polymorphisms at CYP1A1, GSTM1 and GSTT1 loci among Indians: tobacco exposure as a risk modulator. Carcinogenesis 2007;28:1455-62.

28. Ogden GR, Cowpe JG, Chisholm DM, Lane EB. DNA and keratin analysis of oral exfoliative cytology in the detection of oral cancer. Eur $J$ Cancer B Oral Oncol 1994;30B:405-8. 